\title{
Elevated Serum Elaidic Acid Predicts Risk of Repeat Revascularization After Percutaneous Coronary Intervention in Japan
}

\author{
Toshihiko Oshita, MD; Ryuji Toh, MD, PhD; Masakazu Shinohara, MD, PhD; \\ Kenta Mori, MD, PhD; Yasuhiro Irino, PhD; Manabu Nagao, MD, PhD; Tetsuya Hara, MD, PhD; \\ Hiromasa Otake, MD, PhD; Tatsuro Ishida, MD, PhD; Ken-ichi Hirata, MD, PhD
}

Background: Trans-fatty acid (TFA) intake increases the risk of coronary artery disease (CAD). Our previous cross-sectional survey showed that middle-aged patients with CAD in Japan have elevated serum TFA. In this study, we longitudinally investigated whether elevated TFA is a risk factor in the secondary prevention of CAD for the same-age patients.

Methods and Results: A total of 112 patients (age, 21-66 years) who underwent percutaneous coronary intervention were followed up for up to 2 years. Serum elaidic acid was measured using gas chromatography/mass spectrometry as a marker of TFA intake and divided into quartiles. The primary endpoint was ischemia-driven target lesion revascularization (TLR). The hazard ratio (HR) for TLR increased significantly with higher serum elaidic acid $(P<0.01)$. The significant positive trend remained unchanged after adjusting for conventional lipid profile and bare-metal stent usage. In contrast, although triglycerides and low-density lipoprotein cholesterol were positively correlated with elaidic acid, they were not associated with TLR. On multivariable Cox proportional hazard analysis, elevated elaidic acid was independently associated with TLR risk after adjusting for conventional coronary risks (HR, 10.7, $\mathrm{P}<0.01)$.

Conclusions: Elevated elaidic acid is associated with higher TLR rate in middle-aged patients with CAD, suggesting that excessive TFA intake is becoming a serious health problem in Japan.

Key Words: Coronary artery disease; Elaidic acid; Target lesion revascularization; Trans-fatty acid

$\mathbf{T}$ rans-fatty acids (TFA) are defined as unsaturated fatty acids with at least 1 non-conjugated double bond in the trans configuration. While small amounts of TFA are found in ruminant dairy and meat products, the main dietary sources of TFA are industrially produced by partial hydrogenation of vegetable oils, a process that converts unsaturated oils into semisolid fats. ${ }^{1}$ Accumulated epidemiological studies have demonstrated that excessive TFA intake is associated with an increased risk of coronary artery disease (CAD) and sudden cardiac death..$^{2-5}$ Therefore, the World Health Organization (WHO) recommended that the dietary intake of industrial TFA should be $<1 \%$ of the daily energy intake. ${ }^{6}$ Moreover, the WHO has recently issued a statement that industrially produced TFA from the global food supply should be eliminated. ${ }^{7}$ Elaidic acid (trans-9 C18:1) is the trans-isomer of oleic acid (cis-9 C18:1) and the main component of TFA derived from industrial products. Circulating elaidic acid level can be used as an indicator of oral TFA intake because it cannot be synthesized by the body. ${ }^{8}$ Recently, we showed that middle-aged patients with CAD and/or metabolic syndrome have elevated serum elaidic acid compared with those without such conditions in Japan. ${ }^{9}$ Additionally, elevated serum elaidic acid concentration is associated with higher prevalence of vulnerable coronary plaque $^{10}$ and insulin resistance. ${ }^{11}$ Although the Japanese diet is assumed to contain lesser fat including TFA than the Western diet, ${ }^{12,13}$ our previous study alarmingly suggested that excessive TFA intake is becoming a public health problem in Japan as well. ${ }^{9}$

Given, however, that our previous studies were crosssectional surveys, the causal relationship between serum elaidic acid concentration and CAD in Japan was not determined. In the previous survey, we found that serum elaidic concentration was elevated in patients with CAD aged $\leq 66$ years. ${ }^{9}$ In the present study, we investigated

Received October 31, 2018; revised manuscript received January 11, 2019; accepted January 27, 2019; J-STAGE Advance Publication released online March 13, 2019 Time for primary review: 26 days

Division of Cardiovascular Medicine (T.O., M.N., T.H., H.O., T.I., K.H.), Division of Evidence-based Laboratory Medicine (R.T., Y.I., K.H.), Division of Epidemiology (M.S.), Kobe University Graduate School of Medicine, Kobe; Department of General Internal Medicine, Kobe University Hospital, Kobe (K.M.), Japan

Mailing address: Ryuji Toh, MD, PhD, Division of Evidence-based Laboratory Medicine, Kobe University Graduate School of Medicine, 7-5-1 Kusunoki-cho, Chuo-ku, Kobe 650-0017, Japan. E-mail: rtoh@med.kobe-u.ac.jp

ISSN-1346-9843 All rights are reserved to the Japanese Circulation Society. For permissions, please e-mail: cj@j-circ.or.jp 


\begin{tabular}{|c|c|c|c|c|c|}
\hline \multirow[b]{3}{*}{ Variables } & \multicolumn{4}{|c|}{ Serum elaidic acid quartiles $(\mu \mathrm{mol} / \mathrm{L})$} & \multirow{3}{*}{ P-value } \\
\hline & Q1 $[\leq 10.18]$ & Q2 [10.19-13.63] & Q3 [13.64-16.99] & Q4 [ $\geq 17.0]$ & \\
\hline & $(n=28)$ & $(n=28)$ & $(n=28)$ & $(n=28)$ & \\
\hline Age (years) & $58.0 \pm 5.7$ & $60.9 \pm 5.4$ & $57.8 \pm 7.3$ & $56.5 \pm 8.3$ & 0.14 \\
\hline Male & $27(96.4)$ & $22(78.6)$ & $26(92.9)$ & $22(78.6)$ & 0.09 \\
\hline Weight (kg) & $70.0 \pm 12.1$ & $67.1 \pm 11.1$ & $68.6 \pm 13.7$ & $73.8 \pm 8.3$ & 0.21 \\
\hline BMI $\left(\mathrm{kg} / \mathrm{m}^{2}\right)$ & $24.8 \pm 3.4$ & $25.0 \pm 3.8$ & $24.8 \pm 3.8$ & $26.8 \pm 4.0$ & 0.15 \\
\hline Metabolic syndrome & $13(46.4)$ & $13(46.4)$ & $11(39.3)$ & $17(60.7)$ & 0.32 \\
\hline Hypertension & $21(75.0)$ & $22(78.6)$ & $24(85.7)$ & $23(82.1)$ & 0.78 \\
\hline Dyslipidemia & $22(78.6)$ & $24(85.7)$ & $22(78.6)$ & $24(85.7)$ & 0.87 \\
\hline Diabetes mellitus & $17(60.7)$ & $13(46.4)$ & $14(50.0)$ & $16(57.1)$ & 0.73 \\
\hline Smoking & 25 (89.3) & $22(78.6)$ & $22(78.6)$ & $24(85.7)$ & 0.52 \\
\hline Family history & $6(21.4)$ & $15(53.6)$ & $5(17.9)$ & $8(28.6)$ & 0.02 \\
\hline \multicolumn{6}{|l|}{ Laboratory data } \\
\hline Elaidic acid ( $\mu \mathrm{mol} / \mathrm{L})$ & $\begin{array}{c}8.8 \\
(8.0-9.5)\end{array}$ & $\begin{array}{c}11.5 \\
(10.8-12.2)\end{array}$ & $\begin{array}{c}14.8 \\
(14.1-15.7)\end{array}$ & $\begin{array}{c}20.2 \\
(18.8-25.8)\end{array}$ & $<0.001$ \\
\hline T-cho (mg/dL) & $170.5 \pm 30.8$ & $171.4 \pm 47.7$ & $186.5 \pm 37.5$ & $205.8 \pm 37.3$ & $<0.001$ \\
\hline $\mathrm{HDL}-\mathrm{C}(\mathrm{mg} / \mathrm{dL})$ & $48.4 \pm 15.9$ & $44.7 \pm 10.9$ & $49.9 \pm 16.4$ & $41.5 \pm 14.8$ & 0.13 \\
\hline LDL-C (mg/dL) & $93.1 \pm 21.9$ & $100.5 \pm 42.0$ & $105.8 \pm 30.3$ & $126.3 \pm 33.9$ & $<0.01$ \\
\hline $\mathrm{TG}(\mathrm{mg} / \mathrm{dL})$ & $\begin{array}{c}119.5 \\
(100.5-142.0)\end{array}$ & $\begin{array}{c}132.0 \\
(107.5-162.5)\end{array}$ & $\begin{array}{c}147.5 \\
(114.0-211.0)\end{array}$ & $\begin{array}{c}195.0 \\
(137.0-262.0)\end{array}$ & $<0.001$ \\
\hline $\mathrm{HbA1c}(\%)$ & $6.3 \pm 1.6$ & $6.5 \pm 1.1$ & $6.9 \pm 1.5$ & $7.0 \pm 1.0$ & 0.26 \\
\hline hs-CRP (mg/dL) & $\begin{array}{c}0.04 \\
(0.02-0.09)\end{array}$ & $\begin{array}{c}0.06 \\
(0.03-0.19)\end{array}$ & $\begin{array}{c}0.05 \\
(0.03-0.14)\end{array}$ & $\begin{array}{c}0.06 \\
(0.03-0.16)\end{array}$ & 0.57 \\
\hline \multicolumn{6}{|l|}{ Medication at discharge } \\
\hline Statin & $15(53.6)$ & $19(67.9)$ & $15(53.6)$ & $14(50.0)$ & 0.55 \\
\hline Dual antiplatelet therapy & $28(100)$ & $28(100)$ & $28(100)$ & $28(100)$ & 1.00 \\
\hline EPA & $3(10.7)$ & $3(10.7)$ & $2(7.1)$ & 3 (10.7) & 0.96 \\
\hline Fibrates & $0(0)$ & $0(0)$ & $1(3.6)$ & $1(3.6)$ & 0.35 \\
\hline Ezetimibe & $1(3.6)$ & $1(3.6)$ & $0(0)$ & $2(7.1)$ & 0.56 \\
\hline Anti-diabetic agent & $12(42.9)$ & $8(28.6)$ & $7(25.0)$ & $12(42.9)$ & 0.35 \\
\hline \multicolumn{6}{|l|}{ Stent } \\
\hline Bare-metal stent & $1(3.6)$ & $3(10.7)$ & $0(0)$ & $2(7.1)$ & 0.15 \\
\hline Drug-eluting stent & $27(96.4)$ & $25(89.3)$ & $28(100)$ & $26(92.9)$ & 0.42 \\
\hline Total no. stents & $2.4 \pm 1.3$ & $2.1 \pm 1.0$ & $1.8 \pm 1.1$ & $1.9 \pm 1.1$ & 0.21 \\
\hline Total stent length (mm) & $52.6 \pm 38.3$ & $50.9 \pm 35.3$ & $39.4 \pm 28.0$ & $45.1 \pm 36.5$ & 0.58 \\
\hline Maximum stent diameter (mm) & $3.4 \pm 0.2$ & $3.4 \pm 0.3$ & $3.2 \pm 0.5$ & $3.3 \pm 0.4$ & 0.48 \\
\hline Stent overlap & $20(71.4)$ & $19(67.9)$ & $14(50.0)$ & $14(50.0)$ & 0.24 \\
\hline
\end{tabular}

Data given as mean $\pm S D$, median $(I Q R)$ or $n(\%)$. Stent overlap was defined as the presence of two or more stents within a treated lesion and an overlapping stent zone. BMI, body mass index; EPA, purified eicosapentaenoic acid; HbA1c, hemoglobin A1c; HDL-C, high-density lipoprotein cholesterol; hs-CRP, high sensitivity C-reactive protein; LDL-C, low-density lipoprotein cholesterol; Q, quartile; T-cho, total cholesterol; TG, triglycerides.

whether elevated serum elaidic acid could be a predictive risk factor for repeat revascularization after percutaneous coronary intervention (PCI) in the same-age patients with CAD in Japan.

\section{Methods}

\section{Subjects}

The Kobe Cardiovascular Marker Investigation (CMI) registry is a single-center registry of patients with cardiovascular disease (CVD) who were referred to Kobe University Hospital. It started in 2008 to identify blood-based biomarkers that are used in predicting CVD.

Based on the Kobe CMI registry, we enrolled consecutive patients aged between 21 and 66 years from our previous study, ${ }^{9}$ and those who underwent successful PCI with stent placement at Kobe University Hospital because of stable angina or inducible myocardial ischemia between July 2008 and February 2013.

Exclusion criteria were defined as follows: (1) emergency admission; (2) acute heart failure (New York Heart Association functional class IV) and pulmonary hypertension; (3) occurrence of cancer in the last 5 years; (4) serum triglyceride $>400 \mathrm{mg} / \mathrm{dL}$; (5) kidney failure (serum creatinine concentration $>2.0 \mathrm{mg} / \mathrm{dL}$ or hemodialysis); (6) familial hypercholesterolemia; or (7) active inflammation (serum C-reactive protein [CRP] concentration $>1 \mathrm{mg} / \mathrm{dL}){ }^{9}$ Patients who were lost to follow-up were also excluded from the analysis.

\section{Ethics}

The study protocol was in accordance with the ethics 


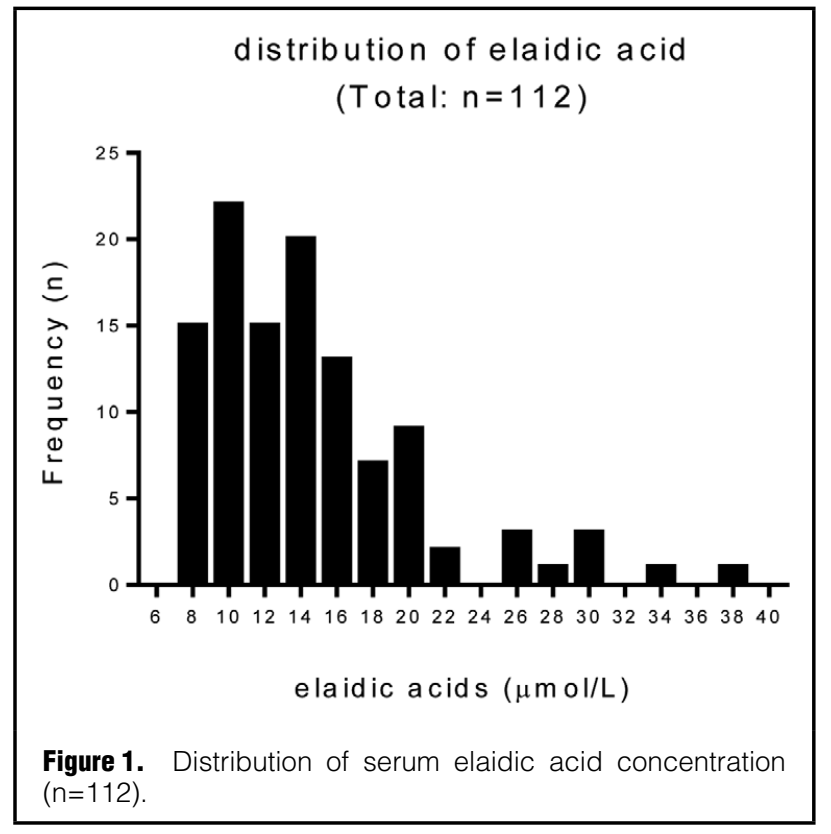

guidelines of the 1975 Declaration of Helsinki. The study was approved by the Ethics Review Committee at Kobe University (Japan) and was registered in the UMIN Clinical Trials Registry with identification number 000030297. Written informed consent was obtained from all patients prior to enrollment in this study.

\section{Study Design}

Blood samples were collected in the morning prior to cardiac catheterization after overnight fasting and stored at $-80^{\circ} \mathrm{C}$ until measurement of elaidic acid concentration. The participants were followed up for up to 2 years after PCI. Clinical outcome data were obtained by reviewing outpatient records or telephone interviews for death, myocardial infarction, stroke, and target lesion revascularization (TLR). The primary outcome was ischemia-driven TLR during the follow-up period.

\section{Serum Elaidic Acid Concentration}

Serum elaidic acid was measured using gas chromatography/ mass spectrometry (GC-MS QP2010; Shimadzu, Kyoto, Japan) at the Integrated Center for Mass Spectrometry of Kobe University Graduate School of Medicine according to the procedure described in our previous report. ${ }^{9}$ A quality control sample $(10 \mu \mathrm{mol} / \mathrm{L}$ elaidic acid standard) was measured in each analytical batch to calibrate serum elaidic acid concentration. The coefficient of variation was $<2 \%$. Serum elaidic acid concentration was divided into quartiles as follows: Q1, $\leq 10.18 \mu \mathrm{mol} / \mathrm{L} ; \mathrm{Q} 2,10.19-13.63 \mu \mathrm{mol} / \mathrm{L}$; Q3, $13.64-16.99 \mu \mathrm{mol} / \mathrm{L}$; and Q4, $\geq 17.0 \mu \mathrm{mol} / \mathrm{L}$.

\section{Other Clinical Variables}

Serum total cholesterol, low-density lipoprotein cholesterol (LDL-C), high-density lipoprotein cholesterol (HDL-C), triglycerides (TG), hemoglobin Alc (HbAlc), and highsensitivity CRP (hs-CRP) were measured using the standard methods. HbA1c ( $\%)$ is expressed as the National Glycohemoglobin Standardization Program (NGSP) equivalent, using the formula HbA1c $(\%)=H b A 1 c$ (Japan Diabetes Society) $(\%)+0.4 \% .{ }^{14}$ Hypertension was defined as blood pressure $\geq 140 / 90 \mathrm{mmHg}$ or treatment with antihypertensive drugs. Diabetes mellitus was defined as $\mathrm{HbAlc} \geq 6.5 \%$ and fasting serum glucose $\geq 126 \mathrm{mg} / \mathrm{dL}$ or non-fasting serum glucose $\geq 200 \mathrm{mg} / \mathrm{dL}$, or treatment with anti-diabetic drugs. Dyslipidemia was defined according to the Japan Atherosclerosis Society Guidelines for Prevention of Atherosclerotic Cardiovascular Diseases ${ }^{\mathbf{1 5}}$ or treatment with anti-hyperlipidemia drugs. Metabolic syndrome was defined according to the Japan Atherosclerosis Society guidelines. ${ }^{\mathbf{1 6}}$

\section{Statistical Analysis}

All statistical analysis was performed using Stata 14.2 (StataCorp, College Station, TX, USA). Two-sided P $\leq 0.05$ was considered statistically significant in all analyses. Categorical variables are expressed as numbers and percentage. Continuous variables are expressed as mean $\pm \mathrm{SD}$, unless otherwise specified. Variables with skewed distribution were normalized using natural logarithmic transformation. The trends in baseline characteristics across serum elaidic acid quartiles were tested using one-way analysis of variance (ANOVA). Moreover, the relationships between 2 numerical variables were investigated on linear regression analysis. The incidence rates of TLR were calculated using the person-year method. Hazard ratio (HR) with $95 \%$ CI of serum elaidic acid levels for TLR was assessed using the Cox proportional hazards model. The trends in the risk of TLR across serum elaidic acid level were tested with the Cox proportional hazards model by assigning ordered numbers (i.e., 1, 2, 3, and 4) to the quartiles. Multivariate analysis was performed to explore the influence of independent variables on TLR.

\section{Results}

\section{Subject Baseline Characteristics}

From the Kobe CMI registry between July 2008 and February 2013, a total of 112 patients were enrolled according to the inclusion and exclusion criteria. Median serum elaidic acid concentration in all participants; in men $(\mathrm{n}=97)$; and in women $(\mathrm{n}=15)$, was $13.6 \mu \mathrm{mol} / \mathrm{L}$ (IQR, $10.2-17.0 \mu \mathrm{mol} / \mathrm{L}$ ), $13.4 \mu \mathrm{mol} / \mathrm{L}$ (IQR, $10.0-16.4 \mu \mathrm{mol} / \mathrm{L}$ ), and $13.7 \mu \mathrm{mol} / \mathrm{L}$ (IQR, 11.5-20.2 $\mu \mathrm{mol} / \mathrm{L})$, respectively. Table 1 lists the baseline subject characteristics according to serum elaidic acid level. A higher prevalence of positive family history of CAD was seen in patients with lower elaidic acid level. Serum total cholesterol, LDL-C, and TG significantly increased with higher elaidic acid. In contrast, mean serum HDL-C was lower in patients with higher elaidic acid, but, the trend across the quartiles was not statistically significant.

\section{Serum Elaidic Acid and Conventional Biomarkers}

We assessed the relationship between serum elaidic acid level and other biomarkers including conventional lipid profiles. Given that the distribution of serum elaidic level was skewed to the left (Figure 1), we normalized serum elaidic acid level by logarithmic transformation prior to analysis. Serum elaidic acid was positively associated with TG, total cholesterol, and LDL-C (Figure 2A-C). In contrast, no significant relationship was noted between serum elaidic acid and HDL-C, HbAlc, and hs-CRP (Figure 2D-F).

\section{Serum Elaidic Acid and Risk of TLR}

During the median follow-up period of 2.0 years (IQR, 
(A)

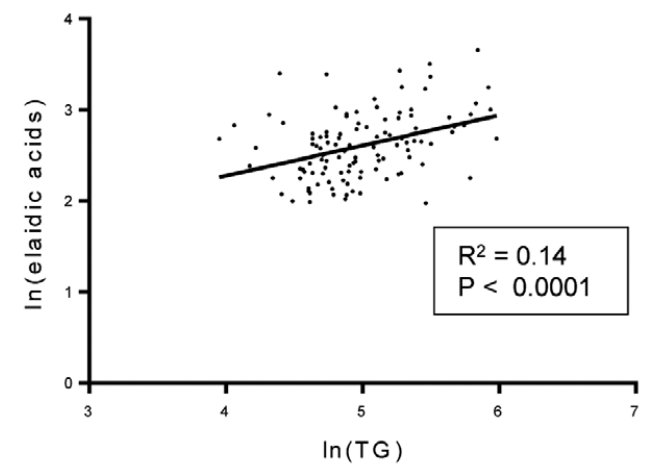

(C)

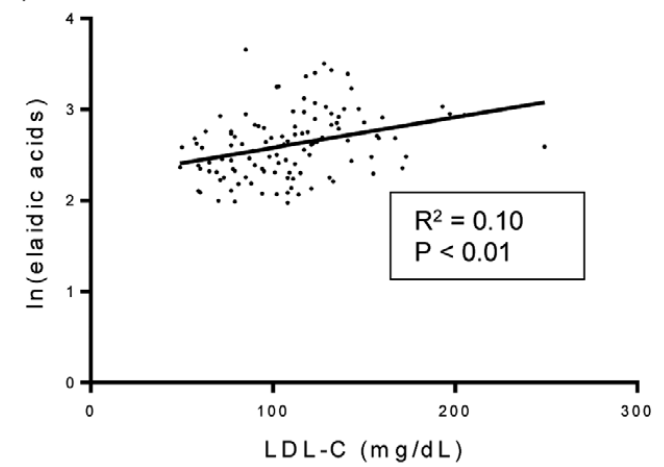

(E)

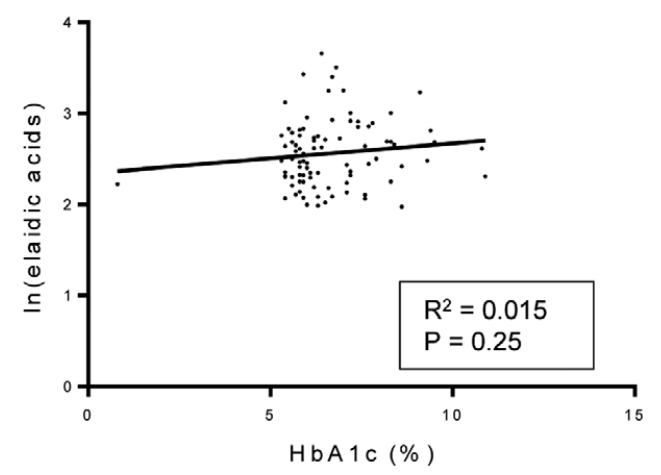

(B)

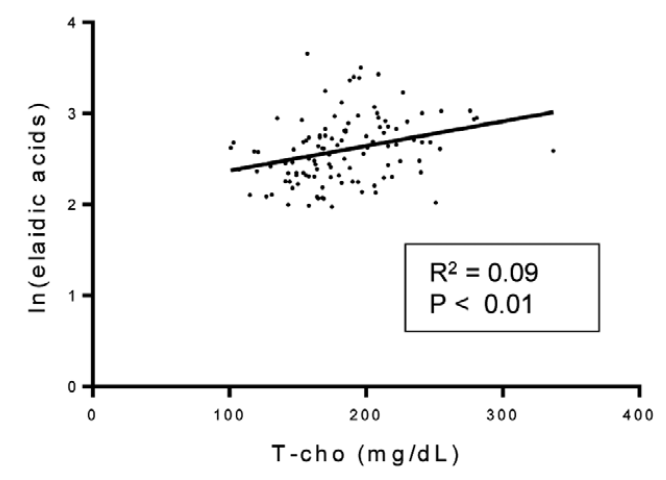

(D)

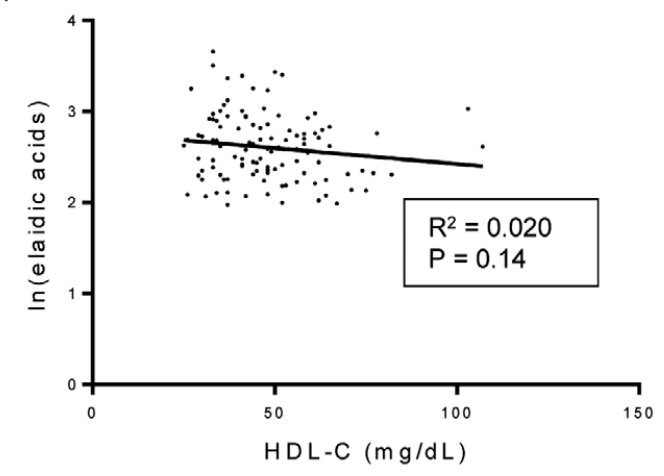

(F)

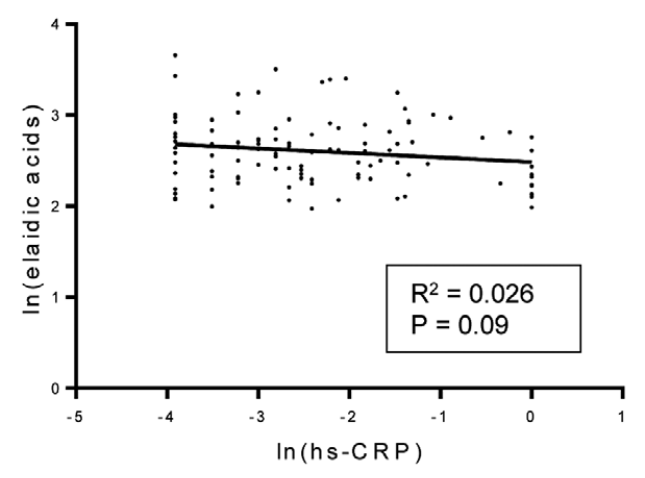

Figure 2. Ln(elaidic acid) vs. (A) In(triglycerides [TG]), (B) total cholesterol (T-cho), (C) low-density lipoprotein cholesterol (LDL-C), (D) high-density lipoprotein cholesterol (HDL-C), (E) hemoglobin A1c (HbA1C), and (F) In(high-sensitivity C-reactive protein [hs-CRP]). In, natural logarithm.

$0.7-2.0$ years), 30 patients $(26.8 \%)$ required TLR. The incidence rates and HR for TLR according to serum elaidic acid quartile are given in Table 2. The HR for TLR increased significantly with higher serum elaidic acid $(\mathrm{P}<0.01)$. In the multivariable model adjusted for conventional lipid profiles, the positive relationship between serum elaidic acid and TLR was also observed. Furthermore, the significant association remained unchanged even after adjusting for the use of bare-metal stents (BMS). In contrast, although TG and LDL-C were positively correlated with elaidic acid level, no significant difference was observed in the HR for TLR according to TG and LDL-C quartile (Table 3). Finally, we found that serum elaidic acid was the only factor associated with the incidence of TLR (Table 4). On multivariate Cox proportional hazard analysis, elaidic acid remained independently associated with TLR after adjusting for traditional coronary risk factors, conventional lipid profiles, and stent parameters (number, length, diameter, and overlap), according to the previous reports (Table 4). ${ }^{17,18}$ In contrast, we omitted the use of anti-platelet medication and BMS from the Cox proportional hazard model, because all participants underwent dual anti-platelet therapy after PCI, and no patients with BMS implantation required TLR in the present study. 


\begin{tabular}{|c|c|c|c|c|c|c|c|c|}
\hline \multirow{2}{*}{$\begin{array}{l}\text { Elaidic acid } \\
\text { quartiles }\end{array}$} & \multirow{2}{*}{$\begin{array}{l}\text { No. TLR/ } \\
\text { subjects }\end{array}$} & \multirow{2}{*}{$\begin{array}{c}\text { Incidence rate } \\
\text { (per } 10^{2} \text { person } \\
\text { years) }\end{array}$} & \multirow[b]{2}{*}{ HR (95\% Cl) } & \multirow[b]{2}{*}{ P-value } & \multicolumn{2}{|c|}{$\begin{array}{c}\text { Multivariable-adjusted } \\
\text { model } 1\end{array}$} & \multicolumn{2}{|c|}{$\begin{array}{c}\text { Multivariable-adjusted } \\
\text { model } 2\end{array}$} \\
\hline & & & & & HR (95\% Cl) & P-value & $\mathrm{HR}(95 \% \mathrm{Cl})$ & P-value \\
\hline Q1 & $3 / 28$ & 5.6 & 1.0 (Ref.) & & 1.0 (Ref.) & & 1.0 (Ref.) & \\
\hline Q2 & $6 / 28$ & 14.8 & $2.6(0.6-10.4)$ & 0.16 & $3.6(0.7-17.6)$ & 0.11 & $4.5(0.9-23.6)$ & 0.08 \\
\hline Q3 & $10 / 28$ & 30.2 & $5.1(1.4-18.7)$ & $<0.01$ & $5.3(1.3-21.5)$ & 0.02 & $5.2(1.3-21.0)$ & 0.02 \\
\hline Q4 & $11 / 28$ & 33.3 & $5.6(1.5-20.1)$ & $<0.01$ & $8.0(1.7-37.5)$ & $<0.01$ & $8.2(1.8-38.2)$ & $<0.01$ \\
\hline $\mathrm{P}$ for trend & & & & $<0.01$ & & $<0.01$ & & $<0.01$ \\
\hline
\end{tabular}

Multivariable model 1 was adjusted for $\mathrm{HDL}-\mathrm{C}, \mathrm{LDL}-\mathrm{C}, \ln (\mathrm{TG})$. Multivariable model 2 was adjusted for the variables in model $1+$ stent type (bare-metal stent). In, natural logarithm; TLR, target lesion revascularization. Other abbreviations as in Table 1.

\begin{tabular}{|c|c|c|c|c|c|c|c|c|c|}
\hline $\begin{array}{c}\text { TG } \\
\text { quartiles }\end{array}$ & $\begin{array}{l}\text { No. TLR/ } \\
\text { subjects }\end{array}$ & $\begin{array}{c}\text { Incidence rate } \\
\text { (per } 10^{2} \text { person } \\
\text { years) }\end{array}$ & $\begin{array}{c}\text { HR } \\
(95 \% \mathrm{Cl})\end{array}$ & P-value & $\begin{array}{l}\text { LDL-C } \\
\text { quartiles }\end{array}$ & $\begin{array}{l}\text { No. TLR/ } \\
\text { subjects }\end{array}$ & $\begin{array}{c}\text { Incidence rate } \\
\text { (per } 10^{2} \text { person } \\
\text { years) }\end{array}$ & $\begin{array}{c}\text { HR } \\
(95 \% \mathrm{Cl})\end{array}$ & P-value \\
\hline Q1 & $5 / 28$ & 11.4 & 1.00 (Ref.) & & Q1 & $7 / 28$ & 16.2 & 1.00 (Ref.) & \\
\hline Q2 & $7 / 28$ & 16.0 & $1.4(0.43-4.3)$ & 0.60 & Q2 & $8 / 28$ & 17.0 & $1.0(0.37-2.8)$ & 0.97 \\
\hline Q3 & $8 / 28$ & 20.4 & $1.7(0.57-5.3)$ & 0.34 & Q3 & $9 / 28$ & 25.9 & $1.5(0.57-4.1)$ & 0.39 \\
\hline Q4 & $10 / 28$ & 29.9 & $2.4(0.84-7.3)$ & 0.10 & Q4 & $6 / 28$ & 18.1 & $1.1(0.35-3.1)$ & 0.92 \\
\hline$P$ for trend & & & & 0.08 & $P$ for trend & & & & 0.66 \\
\hline
\end{tabular}

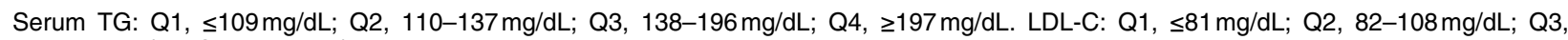
$109-130 \mathrm{mg} / \mathrm{dL} ; \mathrm{Q} 4, \geq 131 \mathrm{mg} / \mathrm{dL}$. Abbreviations as in Tables 1,2 .

\begin{tabular}{|c|c|c|c|c|c|c|}
\hline \multirow{2}{*}{ Variable } & \multicolumn{3}{|c|}{ Univariate } & \multicolumn{3}{|c|}{ Multivariate } \\
\hline & HR & $95 \% \mathrm{Cl}$ & P-value & HR & $95 \% \mathrm{Cl}$ & P-value \\
\hline Ln(elaidic acid) & 4.17 & $1.76-9.88$ & 0.001 & 10.7 & $2.11-54.2$ & 0.004 \\
\hline Age (years) & 1.01 & $0.96-1.07$ & 0.71 & & & \\
\hline Male gender & 0.94 & $0.33-2.69$ & 0.91 & & & \\
\hline Smoking at baseline & 1.54 & $0.47-5.08$ & 0.48 & & & \\
\hline Metabolic syndrome & 0.84 & $0.41-1.78$ & 0.67 & & & \\
\hline Diabetes mellitus & 0.72 & $0.33-1.58$ & 0.42 & & & \\
\hline Hypertension & 1.77 & $0.62-5.07$ & 0.29 & & & \\
\hline $\operatorname{Ln}(T G)$ & 1.68 & $0.72-3.91$ & 0.23 & & & \\
\hline $\mathrm{HDL}-\mathrm{C}(\mathrm{mg} / \mathrm{dL})$ & 1.01 & $0.99-1.03$ & 0.22 & & & \\
\hline LDL-C (mg/dL) & 1.00 & $0.99-1.01$ & 0.71 & & & \\
\hline $\mathrm{HbA1c}(\%)$ & 1.11 & $0.83-1.48$ & 0.47 & & & \\
\hline Ln(hs-CRP) & 1.18 & $0.88-1.59$ & 0.28 & & & \\
\hline Total no. stents & 1.10 & $0.82-1.51$ & 0.48 & & & \\
\hline Total stent length (mm) & 1.00 & $0.99-1.02$ & 0.25 & & & \\
\hline Maximum stent diameter $(\mathrm{mm})$ & 0.77 & $0.28-2.09$ & 0.60 & & & \\
\hline Stent overlap & 2.03 & $0.87-4.73$ & 0.10 & & & \\
\hline
\end{tabular}

Abbreviations as in Tables 1,2.

\section{Discussion}

In our previous cross-sectional survey, serum TFA was found to be elevated in middle-aged patients with CAD and/or metabolic syndrome in Japan. ${ }^{9}$ In the present longitudinal study, we showed that elevated serum elaidic acid was associated with the incidence of TLR in the same-age Japanese generation with CAD. In contrast, although serum elaidic acid level was positively associated with LDL-C and TG, they were not associated with TLR.

TFA are known to worsen the lipid profile by increasing
LDL-C and TG and reducing HDL-C.19-22 In the present study, we also found that elaidic acid level was positively associated with LDL-C and TG. The present findings might also reflect excessive calorie intake in patients with higher elaidic acid. In contrast, serum elaidic acid level was associated with the incidence of TLR, independent of both LDL-C and TG. Particularly, because TFA are components of TG, it is undeniable that elaidic acid merely reflects circulating TG. In contrast to elaidic acid, the HR for TLR according to TG quartile did not show a significant positive trend. And also, we did not observe an inverse relationship 
between elaidic acid and HDL-C. Therefore, the mechanisms underlying the relationship between elevated circulating elaidic acid and the incidence of TLR cannot be attributed to the lipid profile alone.

Excessive TFA intake is also assumed to induce abnormal glucose metabolism ${ }^{\mathbf{1 1 , 2 3 , 2 4}}$ and elevated inflammatory biomarkers. ${ }^{25,26}$ But while mean HbAlc increased in patients with higher elaidic acid, no significant difference was noted in elaidic acid quartiles. In addition, serum hs-CRP was not associated with elaidic acid level. Because approximately half of the present participants were prescribed medications including statins and anti-diabetic agents at the time of enrollment (Table 1), effects of TFA on glucose metabolism and systemic inflammation might be counteracted by medical treatment.

In contrast, it has been assumed that TFA exert direct adverse effects on the arterial wall beyond their impact on the plasma lipid profile. We have recently shown that excessive TFA intake accelerates atherosclerosis by inducing inflammation and oxidative stress in mice. ${ }^{27}$ TFA was also found to induce vascular inflammation and reduce vascular nitric oxide production in endothelial cells. ${ }^{28} \mathrm{We}$ have shown that TFA also promote thrombus formation by aggravating anti-thrombogenic endothelial functions via Toll-like receptors 2 and 4 in mice. ${ }^{29}$ It was also recently suggested that lipid rafts might be a platform for Toll-like receptors for TFA to activate pro-inflammation signaling on cell membranes. ${ }^{30}$ In contrast, TFA promote pro-inflammatory signaling and cell death by stimulating the apoptosis signal-regulating kinase $1 /$ p38 pathway. ${ }^{31}$

In the present study, we demonstrated the relationship between circulating elaidic acid level and the incidence of TLR. Elaidic acid is a typical industrial TFA, produced by partial hydrogenation of vegetable oil. It has also been shown that different TFA subtypes are associated with the risk of CVD. ${ }^{31}$ Because linoleic acid has 2 double bonds in the cis configuration at the 9- and 12- positions, several trans isomers should exist (i.e., trans-9/trans-12 [linoelaidic acid], cis-9/trans-12 and trans-9/cis-12). Of the trans isomers of linoleic acid, circulating linoelaidic acid level has been shown to be associated with total mortality, mainly due to the increased risk of CVD. ${ }^{32}$ Further studies are required to elucidate the impact of each TFA subtype on CVD.

\section{Study Limitations}

Several limitations of the present study should be noted. First, cardiovascular events, such as sudden cardiac death, myocardial infarction, and stroke, did not occur during the follow-up period in the present study, which might be due to the small number of participants and relatively short observation period. Larger prospective studies are required to confirm whether elevated circulating elaidic acid concentration is associated with increased risk of CVD in Japan. Second, the higher prevalence of positive family history of CAD in patients with lower elaidic acid might be due to the conscious maintenance of a proper diet. Given, however, that a questionnaire survey regarding dietary habits was not conducted in the present study, we cannot discuss what kinds of food have particularly created an impact on serum elaidic acid concentration. Third, given that serum elaidic acid was measured only at baseline, changes in circulating elaidic acid during the follow-up period were not considered. Finally, the sample size was too small to conclude that there is a relationship between prescribed medication and serum elaidic acid level. A prospective interventional trial is warranted to address this issue.

\section{Conclusions}

Elevated circulating elaidic acid is associated with the need for repeat revascularization after PCI in middle-aged patients with CAD. This suggests that excessive TFA intake is becoming an alarmingly serious health problem in Japan, as well as in Western countries.

\section{Acknowledgment}

This research was supported by a Grant-in-Aid for Scientific Research (C) JP18K08073 from the Ministry of Education, Culture, Sports, Science and Technology of Japan.

\section{Disclosures}

The Division of Evidence-based Laboratory Medicine of Kobe University Graduate School of Medicine was established by an endowment fund from Sysmex Corporation. The other authors declare no conflicts of interest.

\section{Author Contributions}

T.O. contributed to the study design, data collection and analysis, and manuscript writing. R.T. planned and supervised the study, provided logistic support, and edited the manuscript. M.S. and Y.I. measured serum elaidic acid and provided technical support. K.M. ,M.N. ,T.H. and H.O. provided logistic support. T.I. and K.H. provided logistic support and supervised the study. R.T. is the guarantor and is responsible for the overall content of the study.

\section{References}

1. Teegala SM, Willett WC, Mozaffarian D. Consumption and health effects of trans fatty acids: A review. J AOAC Int 2009; 92: $1250-1257$.

2. Willett WC, Stampfer MJ, Manson JE, Colditz GA, Speizer FE, Rosner BA, et al. Intake of trans fatty acids and risk of coronary heart disease among women. Lancet 1993; 341: 581-585.

3. Mozaffarian D, Katan MB, Ascherio A, Stampfer MJ, Willett WC. Trans fatty acids and cardiovascular disease. $N$ Engl J Med 2006; 354: 1601-1613.

4. Mozaffarian D, Aro A, Willett WC. Health effects of trans-fatty acids: Experimental and observational evidence. Eur J Clin Nutr 2009; 63(Suppl 2): S5-S21.

5. Wanders AJ, Zock PL, Brouwer IA. Trans fat intake and its dietary sources in general populations worldwide: A systematic review. Nutrients 2017; 9: pii: E840.

6. Uauy R, Aro A, Clarke R, Ghafoorunissa R, L'Abbé M, Mozaffarian D, et al. WHO Scientific Update on trans fatty acids: Summary and conclusions. Eur J Clin Nutr 2009; 63(Suppl 2): S68-S75.

7. World Health Organization. WHO plan to eliminate industriallyproduced trans-fatty acids from global food supply. https:// www.who.int/news-room/detail/14-05-2018-who-plan-to-elimi nate-industrially-produced-trans-fatty-acids-from-glo bal-food-supply (accessed May 14, 2018).

8. Saadatian-Elahi M, Slimani N, Chajes V, Jenab M, Goudable J, Biessy C, et al. Plasma phospholipid fatty acid profiles and their association with food intakes: Results from a cross-sectional study within the European Prospective Investigation into Cancer and Nutrition. Am J Clin Nutr 2009; 89: 331 -346.

9. Mori K, Ishida T, Yasuda T, Hasokawa M, Monguchi T, Sasaki $\mathrm{M}$, et al. Serum trans-fatty acid concentration is elevated in young patients with coronary artery disease in Japan. Circ J 2015; 79: 2017-2025.

10. Nagasawa Y, Shinke T, Toh R, Ishida T, Otake H, Takaya T, et al. The impact of serum trans fatty acids concentration on plaque vulnerability in patients with coronary artery disease: Assessment via optical coherence tomography. Atherosclerosis 2017; 265: 312-317.

11. Itcho K, Yoshii Y, Ohno H, Oki K, Shinohara M, Irino Y, et al. Association between serum elaidic acid concentration and insulin resistance in two Japanese cohorts with different lifestyles. $J$ Atheroscler Thromb 2017; 24: 1206-1214.

12. Yamada M, Sasaki S, Murakami K, Takahashi Y, Okubo H, 
Hirota N, et al. Estimation of trans fatty acid intake in Japanese adults using 16-day diet records based on a food composition database developed for the Japanese population. J Epidemiol 2010; 20: 119-127.

13. Research Program for Risk Assessment Study on Food Safety. Executive summary of effects of dietary trans fatty acids on health in Japanese, 2010. Tokyo: Food Safety Commission of Japan, 2010 (in Japanese).

14. Committee of the Japan Diabetes Society on the Diagnostic Criteria of Diabetes Mellitus, Seino Y, Nanjo K, Tajima N, Kadowaki T, Kashiwagi A, et al. Report of the committee on the classification and diagnostic criteria of diabetes mellitus. $J$ Diabetes Investig 2010; 1: 212-228.

15. Teramoto T, Sasaki J, Ueshima H, Egusa G, Kinoshita M, Shimamoto K, et al. Diagnostic criteria for dyslipidemia. Executive summary of Japan Atherosclerosis Society (JAS) guideline for diagnosis and prevention of atherosclerotic cardiovascular diseases for Japanese. J Atheroscler Thromb 2007; 14: 155-158.

16. Matsuzawa Y. Metabolic syndrome: Definition and diagnostic criteria in Japan. J Atheroscler Thromb 2005; 12: 301.

17. Taniwaki M, Stefanini GG, Raber L, Brugaletta S, Cequier A, Heg D, et al. Predictors of adverse events among patients undergoing primary percutaneous coronary intervention: Insights from a pooled analysis of the COMFORTABLE AMI and EXAMINATION trials. EuroIntervention 2015; 11: 391-398.

18. Parasca CA, Head SJ, Milojevic M, Mack MJ, Serruys PW, Morice MC, et al. Incidence, characteristics, predictors, and outcomes of repeat revascularization after percutaneous coronary intervention and coronary artery bypass grafting: The SYNTAX Trial at 5 years. JACC Cardiovasc Interv 2016; 9: 2493-2507.

19. Mensink RP, Katan MB. Effect of dietary trans fatty acids on high-density and low-density lipoprotein cholesterol levels in healthy subjects. $N$ Engl J Med 1990; 323: 439-445.

20. Katan MB, Zock PL, Mensink RP. Trans fatty acids and their effects on lipoproteins in humans. Annu Rev Nutr 1995; 15: 473-493.

21. Hunter JE. Dietary trans fatty acids: Review of recent human studies and food industry responses. Lipids 2006; 41: 967-992.

22. Yang Q, Zhang Z, Loustalot F, Vesper H, Caudill SP, Ritchey $\mathrm{M}$, et al. Plasma trans-fatty acid concentrations continue to be associated with serum lipid and lipoprotein concentrations among US adults after reductions in trans-fatty acid intake. $J$
Nutr 2017; 147: 896-907.

23. Tsutsui W, Fujioka Y. Is the association between dietary trans fatty acids and insulin resistance remarkable in Japan? J Atheroscler Thromb 2017; 24: 1199-1201.

24. Liu B, Sun Y, Snetselaar LG, Sun Q, Yang Q, Zhang Z, et al Association between plasma trans-fatty acid concentrations and diabetes in a nationally representative sample of US adults. $J$ Diabetes 2018; 10: 653-664.

25. Lopez-Garcia E, Schulze MB, Meigs JB, Manson JE, Rifai N, Stampfer MJ, et al. Consumption of trans fatty acids is related to plasma biomarkers of inflammation and endothelial dysfunction. $J$ Nutr 2005; 135: 562-566.

26. El-Saed A, Masaki K, Okamura T, Evans RW, Nakamura Y, Willcox BJ, et al. The associations of C-reactive protein with serum levels of polyunsaturated fatty acids and trans fatty acids among middle-aged men from three populations. $J$ Nutr Health Aging 2016; 20: 16-21.

27. Monguchi T, Hara T, Hasokawa M, Nakajima H, Mori K, Toh $\mathrm{R}$, et al. Excessive intake of trans fatty acid accelerates atherosclerosis through promoting inflammation and oxidative stress in a mouse model of hyperlipidemia. J Cardiol 2017; 70: 121127.

28. Iwata NG, Pham M, Rizzo NO, Cheng AM, Maloney E, Kim F. Trans fatty acids induce vascular inflammation and reduce vascular nitric oxide production in endothelial cells. PLoS One 2011; 6: e29600.

29. Kondo K, Ishida T, Yasuda T, Nakajima H, Mori K, Tanaka N, et al. Trans-fatty acid promotes thrombus formation in mice by aggravating antithrombogenic endothelial functions via Toll-like receptors. Mol Nutr Food Res 2015; 59: 729-740.

30. Pan Y, Liu B, Deng Z, Fan Y, Li J, Li H. Lipid rafts promote trans fatty acid-induced inflammation in human umbilical vein endothelial cells. Lipids 2017; 52: 27-35.

31. Hirata Y, Takahashi M, Kudoh Y, Kano K, Kawana H, Makide $\mathrm{K}$, et al. Trans-fatty acids promote proinflammatory signaling and cell death by stimulating the apoptosis signal-regulating kinase 1 (ASK1)-p38 pathway. J Biol Chem 2017; 292: 81748185.

32. Wang Q, Imamura F, Lemaitre RN, Rimm EB, Wang M, King IB, et al. Plasma phospholipid trans-fatty acids levels, cardiovascular diseases, and total mortality: The cardiovascular health study. $J$ Am Heart Assoc 2014; 3: pii: e000914. 